\title{
Thermodynamic Simulation of a Detached House with District Heating Subcentral.
}

\author{
J. Gustafsson, J. Delsing, J. van Deventer \\ Div. of EISLAB \\ Dept. of Computer Science and Electrical Engineering \\ Luleå University of Technology, \\ SE-971 87 Luleå, Sweden \\ Phone: +46920 493006, E-mail: j.gustafsson@1tu.se.
}

\begin{abstract}
A physical thermodynamic model of a detached house connected to a low-tempered district heating network is presented. The model is created in Mathworks Simulink $\AA$ with a pedagogic approach in mind, e.g. masked subsystems divided in to physical components. The house model is easily modified to any detached house. Provision is also made to make it scalable to multi-family houses. The district heating substation modeled is a parallel coupled plate heat exchanger, which is the most common substation in smaller buildings such as villas. The purpose of creating the model was to provide a platform for test and evaluation of new control methods for district heating system based on wireless sensor networks. Initial validation of the model is presented.
\end{abstract}

Keywords - District heating, simulation, energy, heat.

\section{INTRODUCTION}

With the objective of testing new control theories for substations in district heating systems this computer model was developed. Target systems are detached houses with waterborne heating system. The work is based on earlier work by Wollerstrand, Persson, Yliniemi and others [3], [6], [4]. Similar thermal simulations in Simulink have also been done by others, for example [7].

This paper describes the most important parts of the model. The present work has both improvement regarding the functional model as well as from a usability perspective. Such examples are masking of Simulink blocks and removal of huge configuration files. The model overview has also been improved by re-arranging the blocks in a more pedagogical way. The exterior walls, roof and floor have also been improved to act more realistic to the type of houses it is created to resemble.

With continuously increasing energy demand worldwide and global warming as its side effect, increased energy efficiency in present and future energy supply chains is an important issue. District heating (DH) has proved to be an environmental friendly, reliable heat-energy source suitable for all relatively dense populated areas in cold climate zones. The heat-energy is often a by-product of industrial processes or electrical power production [8], [2], [9]. In the case that the energy is a bi-product from a power-plant, the plant is normally referred to as a combined heat and power plant (CHP). The waste heat produced in the electricity production is cooled in the district heating network, hence it is important to have good cooling capability in the DH network, to keep the efficiency high. Combined heat and power plants normally have a total fuel efficiency around 80\% (includes heat energy), which can be compared to a regular power plant that has an efficiency of around $40 \%$ [8], [9], cf. Fig. 1. This makes district heating a cheap, reliable and environmental friendly heat energy technique that is commercially available today. The heat in a DH system is transported to its customers through extensive underground pipe networks by water or steam.

At the customer, the energy is usually transferred to a house internal radiator and tap water system in a so called district heating subcentral/substation (DHS), see Fig. 2. There are several different types of DHS's, the most common versions in Sweden are the two-stage coupled and the parallel coupled versions. Two-stage substations are primarily used in buildings with larger energy demands, such as apartment buildings and industries. In smaller buildings such as detached houses, the parallel version is preferred as it is more compact and cheaper to produce and install. The tendency on the Swedish market is that parallel substations are used more frequently even in buildings with larger energy consumption [10]. In this article, we have focused on parallel coupled substations.

In Sweden and other countries in the Northern Europe, the total heat-energy consumption for each building connected to the district heating network is measured and billed for. The energy meter measures the primary flow, incoming water temperature and returning temperature (their difference being referred as $\Delta T$ ) of the DHS, and calculates the energy consumption according to (6). There are different ways to debit the
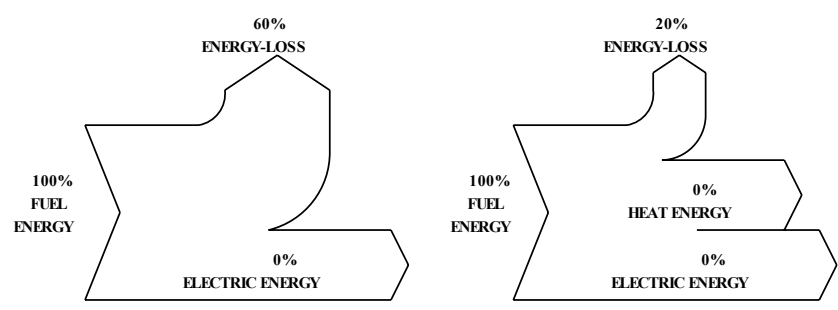

Fig. 1. Energy efficiency of combined heat and power plant (CHP). 


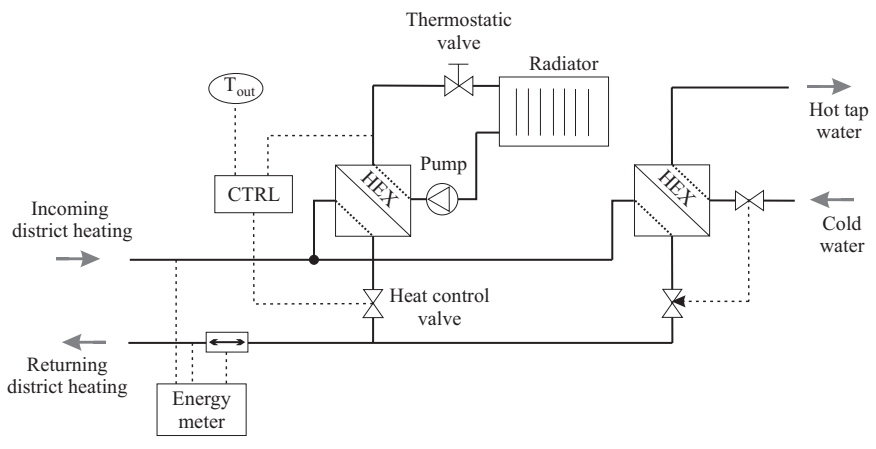

Fig. 2. Parallel coupled district heating substation.

used energy, one of the most fair and reasonable energy tariffs is the flow-dependent debit. By using flow-dependent tariffs, the customer get rewarded with a smaller energy bill when keeping a low primary flow (high $\Delta T$ ) through the substation. This is also what the energy-companies need, as they will receive cooler water back from the district heating network and can expand their network with more paying customers without increasing the power in the CHP or add extra energy sources to the net. To maximize the profit for the energy companies, the temperature drop in the DH-system should be as big as possible over the subcentral. Energy losses in the distribution network are unavoidable but are minimized by using wellinsulated pipes. It is furthermore beneficial to keep the temperature level in the network at a moderate level so the temperature gradient to the surrounding material is kept at a reasonable level. Low tempered systems with an outgoing temperature between 70 and $110^{\circ} \mathrm{C}$ are found to be energy efficient, and are hence used at a large extent.

By increasing the temperature drop $(\Delta T)$ over the DH subcentral the customer will in the case of flow-dependent energy tariff be rewarded with a smaller energy bill, as the same amount of energy can be transferred with a lower flow, (see (6)). The financial winnings for the energy companies are that they can expand the DH network to include more paying customers and get a bigger market share. The environment is also affected in a positive way as the energy being used more efficient, and hence the $\mathrm{CO}_{2}$ emissions will be limited.

Today's subcentral control systems does not consider the primary temperatures $(\Delta T)$ as they normally are not monitored by the heating control system. Currently, the control system look at the temperature of the radiator circuit and control the valve limiting the flow of the primary circuit through the heat exchanger. However, the primary temperatures are measured by the energy meter. If the information from the energy meter would be shared with the control system, the primary return temperature could be considered allowing an active control to enhance $\Delta T$. This would further more improve the prerequisites for error detection in the distribution network and substations. Our idea is to introduce the energy meter data to the control system using wireless sensor networks.
TABLE I. Nomenclature

\begin{tabular}{|c|c|c|}
\hline$a_{e x}$ & Air exchange rate & {$[\mathrm{kg} / \mathrm{s}]$} \\
\hline$A$ & Area & {$\left[\mathrm{m}^{2}\right]$} \\
\hline$c_{p}$ & Constant pressure specific heat & {$[\mathrm{J} / \mathrm{kg} \cdot \mathrm{K}]$} \\
\hline$\stackrel{C}{C}$ & Electric capacitance & {$[\mathrm{F}]$} \\
\hline$h$ & Heat transfer coefficient & {$\left[\mathrm{W} / \mathrm{m}^{2} \cdot \mathrm{K}\right]$} \\
\hline$I$ & Electric current & {$[\mathrm{A}]$} \\
\hline$k$ & Thermal conductivity & {$[\mathrm{W} / \mathrm{m} \cdot \mathrm{K}]$} \\
\hline$L$ & Length/Thickness & {$[\mathrm{m}]$} \\
\hline$L M T D$ & Logarithmic Mean & {$[\mathrm{K}]$} \\
\hline & Temperature Difference & \\
\hline$m$ & Mass & {$[\mathrm{kg}]$} \\
\hline$\dot{m}$ & Mass flow & {$[\mathrm{kg} / \mathrm{s}]$} \\
\hline$n$ & Radiator constant & {$[-]$} \\
\hline$q$ & Heat current & [W] \\
\hline$R$ & Thermal resistance & {$[\mathrm{K} / \mathrm{W}]$} \\
\hline & Electric resistance & {$[\Omega]$} \\
\hline$T$ & Temperature & {$\left[\mathrm{K},{ }^{\circ} \mathrm{C}\right]$} \\
\hline$U$ & Overall heat transfer coef. & {$\left[\mathrm{W} / \mathrm{m}^{2} \cdot \mathrm{K}\right]$} \\
\hline$V$ & Electric voltage, volume & {$\left[\mathrm{V}, \mathrm{m}^{3}\right]$} \\
\hline$\rho$ & Density & {$\left[\mathrm{kg} / \mathrm{m}^{3}\right]$} \\
\hline$\sigma$ & Stefan-Boltzmann constant & {$\left[\mathrm{W} / \mathrm{m}^{2} \cdot \mathrm{K}^{4}\right]$} \\
\hline$\Theta_{m}$ & True temperature difference & {$[\mathrm{K}]$} \\
\hline \multicolumn{3}{|c|}{ Index } \\
\hline$c$ & Cold side & \\
\hline$c d$ & Conduction & \\
\hline$c v$ & Convection & \\
\hline$f r$ & Flow resistance & \\
\hline$h$ & Hot side & \\
\hline$i$ & Numeric index & \\
\hline$i n$ & Inlet, indoor & \\
\hline$i n t$ & Interior & \\
\hline$l c$ & Lumped capacity & \\
\hline out & Outlet, outdoor & \\
\hline$r$ & Radiation & \\
\hline$s f$ & Space heating forward & \\
\hline$s r$ & Space heating return & \\
\hline$w$ & Water, wall & \\
\hline
\end{tabular}

\section{THEORY}

The advantage of this model is that it encapsulates the dynamics or time changing aspect of heat storage. That is when the weather changes, the indoor temperature does not change instantly but follow the laws of physics. The thermodynamic behavior is achieved by physical modeling of the essential parts in a DH connect detached house, such as walls, radiators, heatexchangers and control systems. The varying district heating supply water temperature, to compensate for weather variations, is also taken into consideration and modeled. Further improvements of the model would be, e.g. pressure disturbances (pulsations) in the distribution network caused by several district heating substations reacts simultaneously.

We choose to present some of the thermodynamic relations with direct comparison to electrical circuits, as most control engineers are electrical engineers. There is not enough space to explain every detail of the model in this paper, so we have focused to explain the most essential parts separately before assembling the whole system and show its performance.

\section{A. Thermodynamic fundamentals}

The thermodynamic relations needed to form the thermodynamic model are briefly recalled in this section. 


\section{A.1 One-dimensional conduction}

One-dimensional heat conduction can be derived from Fourier's law in one dimension, (1), where $\frac{d T}{d x}$ is the temperature gradient, and as the heat flows from high to low it also brings the minus sign, $k$ the thermal conductivity and $A$ the area of the heat flow section. Eq. (1) can be rewritten as (2), if the area and thermal conductivity is presumed constant.

$$
\begin{gathered}
q_{c d}=-k A \frac{d T}{d x} \\
q_{c d}=\frac{k A \Delta T}{L}=\frac{\Delta T}{\left(\frac{L}{k A}\right)}=\frac{\Delta T}{R_{c d}}
\end{gathered}
$$

Eq. (2) is analogous with Ohm's law, where the heat current $q$ corresponds to the electrical current $I$, section conductive resistance $R_{c d}$ to the electrical resistance $R$ and the temperature difference $\Delta T$ to the voltage $V$.

\section{A.2 Lumped-capacity heating and cooling}

The comparison to electrical calculations can also be used to show the similarity between thermal heat capacity and electrical capacity. The electrical current through a capacitor is described by (3). A heat current through a wall with theoretically no thermal resistance, but heat capacity capabilities is described in (4), by comparing it with (3), one can clearly see the similarities.

$$
\begin{gathered}
I=\frac{d V}{d t} C \\
q_{l c}=\frac{d T}{d t} c_{p} m
\end{gathered}
$$

A.3 Convection

The thermal heat transport from a surface to a liquid or gas in motion or vice versa is described in (5), where $T_{1}$ and $T_{2}$ are the temperatures of the interacting mediums.

$$
q_{c v}=h A\left(T_{1}-T_{2}\right)
$$

A.4 Flow resistance

The power emitted by a flow of gas or liquid that does not undergo a phase change, but a change in temperature can be calculated by using (6).

$$
q_{f r}=\dot{m} c_{p}\left(T_{\text {in }}-T_{\text {out }}\right)
$$

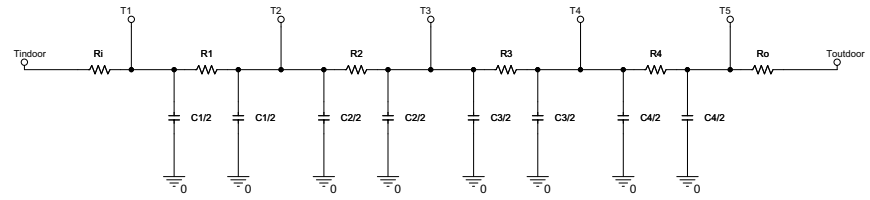

Fig. 3. RC equivalent circuit of a wall. Showing clearly the heat storage elements (capacitors) and heat resistance (resistors).

\section{A.5 Radiation}

The radiation between two surfaces or between a surface and its surroundings is not linearly dependent on the temperature difference like the conduction and convection. The mathematical expression for radiation can be seen in (7). For smaller temperature differences, (7) can be linearized to (8) according to [1]. There are also other methods to calculate the radiative energy available, such as the Logarithmic Mean Temperature Method that is described in section $\mathrm{C}$.

For more information regarding thermodynamic fundamentals, see [1], [11], [12].

$$
\begin{gathered}
q_{r}=\sigma A F\left(T_{1}^{4}-T_{2}^{4}\right) \\
q_{r}=h_{r} A\left(T_{1}-T_{2}\right)
\end{gathered}
$$

where $h_{r}=\sigma F\left(T_{1}^{2}+T_{2}^{2}\right)\left(T_{1}+T_{2}\right)$

\section{B. Thermodynamic building}

The thermodynamic behavior of a building depends on several factors, such as size and construction material. All the parameters that affects the thermodynamic behavior of the model can easily be changed in this model by simply clicking the block of interest and edit the parameter of interest.

B.1 External area (walls, roof, floor etc.)

The temperature between every layer of the wall can be calculated using Kirchoff's current law [13]. The wall can be looked upon as an electrical circuit, cf. 3, where the currents corresponds to the heat current. Equation (9) show how the temperature of the inner wall $\left(T_{1}\right)$ is calculated, corresponding calculations for internal wall sections is explained in (10), eq. (11) provides the exterior wall temperature.

$$
q_{c v}=q_{c d}+q_{l c}
$$

$$
\begin{gathered}
h_{i n}\left(T_{i n}-T_{i}\right)=\frac{k_{i}}{L_{i}}\left(T_{i}-T_{i+1}\right)+\frac{d T_{i}}{d t}\left(\frac{c_{p, i} \rho_{i} L_{i}}{2}\right) \\
\frac{d T_{i}}{d t}=\frac{h_{i n}\left(T_{i n}-T_{i}\right)-\frac{k_{i}}{L_{i}}\left(T_{i}-T_{i+1}\right)}{\frac{c_{p, i} \rho_{i} L_{i}}{2}}
\end{gathered}
$$




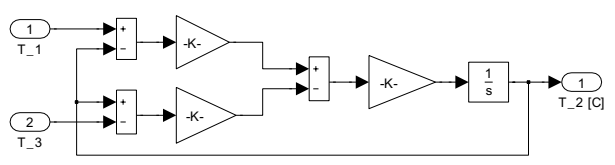

Fig. 4. One layer of the wall.

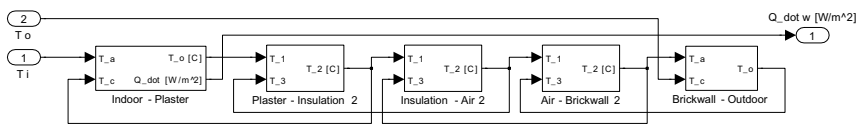

Fig. 5. Four-layer wall model.

$$
\frac{d T_{i}}{d t}=\frac{\frac{k_{i}}{L_{i}}\left(T_{i-1}-T_{i}\right)-\frac{k_{i+1}}{L_{i+1}}\left(T_{i}-T_{i+1}\right)}{\frac{c_{p, i} \rho_{i} L_{i}}{2}+\frac{c_{p, i+1} \rho_{i+1} L_{i+1}}{2}}
$$

Where $i=2 \ldots(N-1)$

$$
h_{\text {out }}\left(T_{i}-T_{\text {out }}\right)=\frac{k_{i}}{L_{i}}\left(T_{i-1}-T_{i}\right)+\frac{d T_{i}}{d t}\left(\frac{c_{p, i} \rho_{i} L_{i}}{2}\right)
$$

$$
\frac{d T_{i}}{d t}=\frac{h_{\text {out }}\left(T_{i}-T_{\text {out }}\right)-\frac{k_{i}}{L_{i}}\left(T_{i-1}-T_{i}\right)}{\frac{c_{p, i} \rho_{i} L_{i}}{2}}
$$

\section{Where $i=N$}

Each of the above explained thermal relationships can of course be created in Simulink, see Fig. 4 for an example of how a single layer is realized in Simulink. The layers are connected together to form a complete model of the wall, this can be seen in Fig. 5, observe the second output of the first block that tells us what the current heat flow is.

B.2 Internal mass thermodynamics.

The thermodynamic interior, like inner walls and furniture can be compared with another RC-net, see Fig. 6. Readers having knowledge in electronics will find it is easy to see the similarities between the charging of a capacitor and the heating of an object.

The object is heated or cooled by the surrounding air by convection, it could also be discussed if the direct radiative heat from the radiators should be included, but in section $\mathrm{C}$

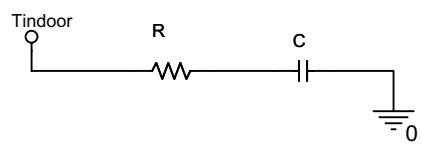

Fig. 6. RC-equivalent for thermodynamic interior.

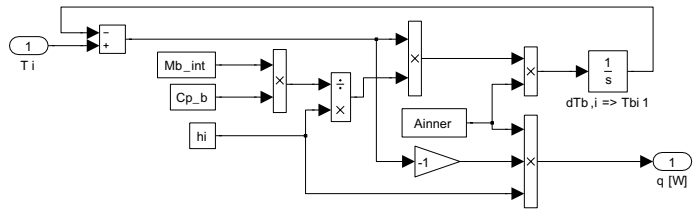

Fig. 7. Internal thermodynamics.

we see that all heat from the radiators transfers to the indoor air. The mathematical relations of the internal thermodynamics can be seen in (12) and a figure of a Simulink realization can be viewed in Fig. 7. Observe that no consideration of thermal conduction to external walls, floor and roof has been taken.

$$
\begin{gathered}
q_{c v}=q_{l c} \\
h_{\text {int }} A\left(T_{i n}-T_{i n t}\right)=\frac{d T_{\text {int }}}{d t}\left(c_{p, i n t} m_{\text {int }}\right) \\
\frac{d T_{i n t}}{d t}=\frac{h_{i n t} A\left(T_{i n}-T_{i n t}\right)}{c_{p, i n t} m_{i n t}}
\end{gathered}
$$

\section{B.3 Assembled building}

When all the exterior and interior Simulink block are connected, we get the mode shown in Fig. 8. This represents the complete building of interest, in our case a two-floor detached house with the sides measuring approximately $10 * 20$ meters, which gives us an approximate total ground area of $200 \mathrm{~m}^{2}$. The house is of brick-wall construction and is build on a slope so half of the bottom floor is under ground. As the house is located in the far north of Sweden (not very far from the arctic circle), and the interesting time of investigation is winter, we have not included sun-radiation as a part of the heating. Internal heat sources like humans, computers and televisions etc. have though been included and can easily be adjusted to fit the certain circumstances or lifestyles. The internal heat sources is simply added to the "heat balance" (13), see also Fig. 8. The air exchange rate in the building can also easily be adapted to suitable levels, in our case this should probably be set to a very low level as the time of interest is winter and there less than 5 people living in the house.

$$
\frac{d T}{d t}=\sum(q)-a_{e x}
$$




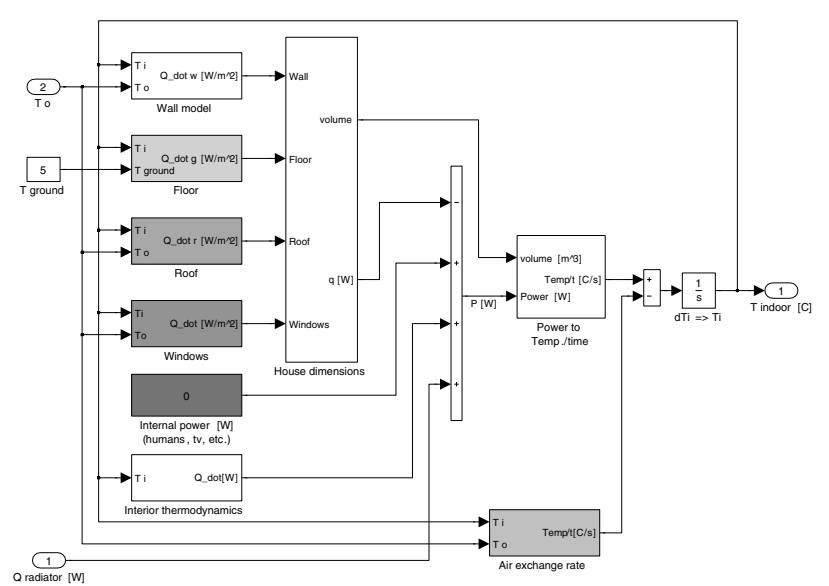

Fig. 8. Complete building.

\section{Radiator}

We now consider the heating system within the house. The supplied power to the radiator is described by (6), this can be adapted to support our application in a better way by applying the Logarithmic Mean Temperature Difference ( $L M T D$ ) method described in [1], [11]. The LMTD describes the temperature difference between the surrounding air and the water in the radiator along the radiator, see (14). By replacing the temperature difference $\left(T_{1}-T_{2}\right)$ in (8) with the true temperature difference $\Theta_{m}$, which in this case is the $L M T D$ we retain (15) where $U$ is the overall heat transfer coefficient (see (16)) and $F$ is a correction factor depending on pressure, capacity rate ratio and flow arrangement [1]. The correction factor could also be expressed as an approximate radiator constant $n$, see (17). The radiator constant can be set to approximately 1.3 according to [5], also see SS EN-442 [16].

In a static case the supplied power would be equal to the radiated power. But when dynamics are introduced, the supplied power will not be equal to radiated power because there is a thermal inertia in the system. Hence the lumped capacity equation (4) can be used to describe this phenomenon.

When setting the difference between the supplied power and radiated power equal to the lumped capacity (18a) it is possible to calculate the return temperature from the radiator, see (18), and Fig. 9.

$$
\begin{gathered}
\Theta_{m}=L M T D=\frac{T_{s f}-T_{\text {sr }}}{\ln \left(\frac{T_{s f}-T_{\text {indoor }}}{T_{\text {sr }}-T_{\text {indoor }}}\right)} \\
q=U A F \Theta_{m} \\
U=\frac{1}{\frac{1}{h_{c}}+\frac{1}{h_{h}}+R_{d c}+R_{d h}}
\end{gathered}
$$

Where in this case $R_{d c}=R_{d h}=0$

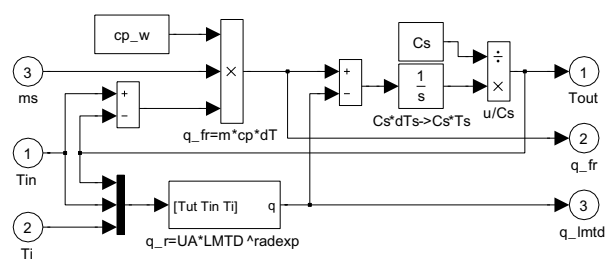

Fig. 9. Radiator model.

$$
\begin{gathered}
q_{r}=U A \Theta_{m}^{n} \\
q_{l c}=q_{f r}-q_{r}
\end{gathered}
$$

$$
\begin{array}{r}
\frac{d T_{s r}}{d t} m_{s} c_{p, w}=c_{p, w} \dot{m}_{s}\left(T_{s f}-T_{s r}\right)-U A \Theta_{m}^{n} \\
\frac{d T_{s r}}{d t}=\frac{c_{p, w} \dot{m}_{s}\left(T_{s f}-T_{s r}\right)-U A \Theta_{m}^{n}}{m_{s} c_{p, w}}
\end{array}
$$

\section{Heat exchangers}

Heat exchangers are very similar to radiators. Basically they are the same, but here the $L M T D$ can not be calculated as we do not know the outlet temperature of the heat exchanger or the surrounding temperature (the temperature in the other chamber). Hence the heat exchanger is split into linear sections that can be connected to form a realistic model of the heat exchanger.

The heat supplied to each section of the heat exchanger is described in (6), the heat is "absorbed" by convection in the separating wall, and then transfered to the fluid of the secondary circuit. The temperature "delay" can be described by (4). In (19) the resulting output temperature from a fluid flow through a heat exchanger section is shown.

$$
\begin{gathered}
q_{l c}=q_{f r}-q_{c v} \\
\frac{d T_{\text {out }}}{d t} m c_{p, \text { water }}=\dot{m} c_{p, \text { water }}\left(T_{\text {in }}-T_{\text {out }}\right)- \\
-h A\left(\frac{T_{\text {in }}+T_{\text {out }}}{2}-T_{w}\right) \\
\frac{d T_{\text {out }}}{d t}=\frac{\dot{m} c_{p, \text { water }}\left(T_{\text {in }}-T_{\text {out }}\right)-h A\left(\frac{T_{\text {in }}+T_{\text {out }}}{2}-T_{w}\right)}{m c_{p, \text { water }}}
\end{gathered}
$$

The temperature of the wall separating the two heat carriers can be calculated in a similar way, see (20).

$$
q_{l c}=q_{c v, h}-q_{c v, c}
$$




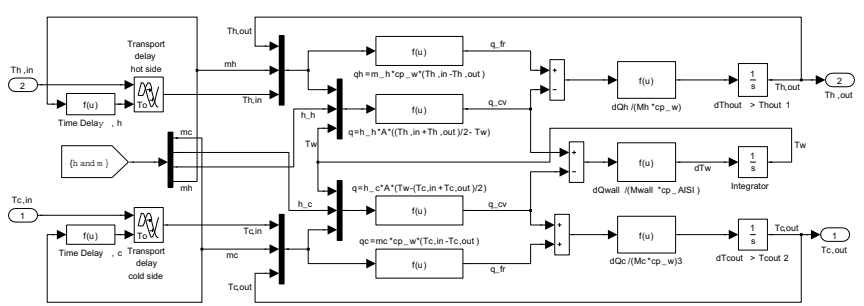

Fig. 10. Heat exchanger section.

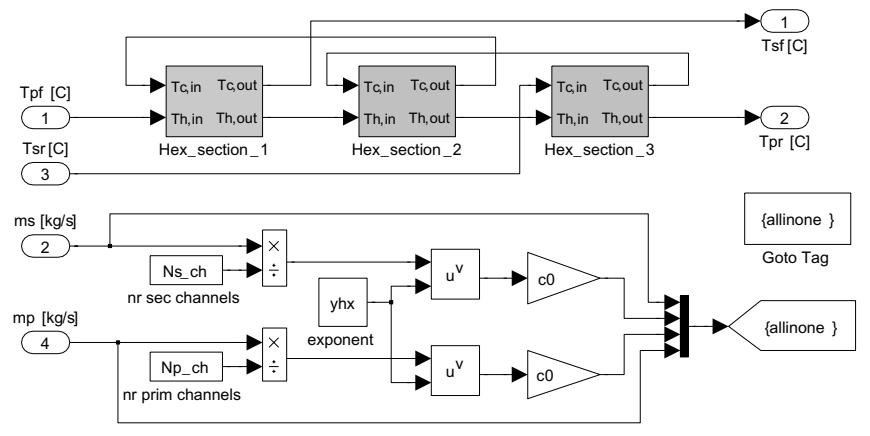

Fig. 11. Complete heat exchanger.

$$
\begin{gathered}
\frac{d T_{w}}{d t} m_{w} c_{p, w}=h_{c} A_{c}\left(T_{w}-\frac{T_{\text {in }, c}+T_{\text {out }, c}}{2}\right)- \\
-h_{h} A_{h}\left(\frac{T_{\text {in }, h}+T_{\text {out }, h}}{2}-T_{w}\right) \\
\frac{d T_{w}}{d t}=\frac{h_{c} A_{c}}{m_{w} c_{p, w}}\left(T_{w}-\frac{T_{\text {in }, c}+T_{\text {out }, c}}{2}\right)- \\
-\frac{h_{h} A_{h}}{m_{w} c_{p, w}}\left(\frac{T_{\text {in }, h}+T_{\text {out }, h}}{2}-T_{w}\right)
\end{gathered}
$$

A Simulink block is created for each section of the heat exchanger, a block can be viewed in Fig. 10. Several of these blocks can be connected to form a more realistic heat exchanger, see Fig. 11, but the more sections, the heavier the calculations of the model becomes, so a trade-off has to be done. In this case we have used 3 sections. Also see [6] and [4] for information regarding heat exchanger simulations.

E. Thermostatic valve

The thermostatic valve controls the flow through the radiator by sensing the room temperature, the colder the room temperature, the higher flow, see (21). Hysteresis can be enabled to make the valve behave more realistic.

$$
\dot{m}=f\left(T_{\text {err. }}\right) \frac{\sqrt{\Delta P_{\text {valve }}} K_{v s} \rho}{3600}
$$

Where $f\left(T_{e r r .}\right)$ is the valve characteristics, here described by a look-up table that translates the indoor temperature error to a valve position. Also see Fig. 12 for an overview of the thermostatic valve realized in the Simulink environment.

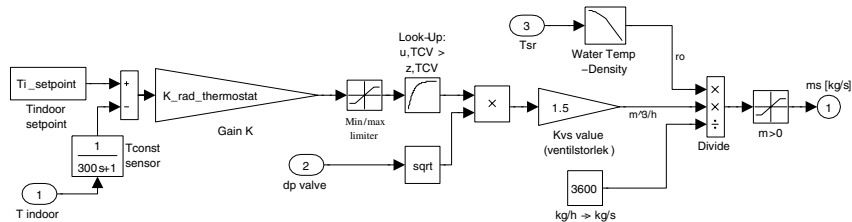

Fig. 12. Thermostatic valve.

\section{F. Radiator circuit controls}

The space heating control system is set to supply the radiators with a preset temperature that is dependent on the outdoor temperature, this is often referred to as a control-curve. The control-curve should be adapted so the thermostatic valves in the radiator circuit have to compensate as little as possible even at big outdoor temperature changes. By doing this, a relatively constant indoor climate can be sustained even if a thermostatic valve should break down.

In this model a regular PI-control (22) system is used to control the radiator supply temperature from the difference between current preset radiator supply temperature (from the control curve) and true radiator supply temperature as control parameter. The control signal steers a valve on the primary side of the heat-exchanger to adjust the flow through the heatexchanger, hence the desired amount of energy can be controlled.

$$
u\left(T_{\text {err. }}\right)=K_{r} T_{\text {err. }}+K_{i} \int_{0}^{t} T_{\text {err. }} d t
$$

\section{SIMULATION RESULT}

The model is tested using several climate conditions, radiator sizes, heat exchangers, building sizes etc. However, due to space limitation in this article we only present results from one simulation set up, see table II and III for the most essential parameters.

To test the realism of the model, a 3 day simulation with realistic circumstances is set up and run. The outdoor temperature is set to simulate a quite cold, but not uncommon period of time with temperatures varying between -5 and $-20^{\circ} \mathrm{C}$. The indoor temperature is set to $21^{\circ} \mathrm{C}$. Double glass windows with a total area of $40 \mathrm{~m}^{2}$ are used. House dimensions and heat exchanger data can be found in table II. The total radiator power in set to $17 \mathrm{~kW}$ when the temperature program in the radiator circuit is $60^{\circ} \mathrm{C}$ out and the returning water is $40^{\circ} \mathrm{C}$, this results in a maximum flow of $0.2 \mathrm{~kg} / \mathrm{s}$ in the radiator circuit when thermostatic valves are fully opened. The walls are set up to resemble the walls of the villa, wall specifications can be studied in table III (the numbers in this table are approximations).

In Fig. 13 the key temperatures and flows in the radiator heat exchanger are plotted for a 72 hour period of time. The thermodynamic behavior of the wall for the same period of time 
TABLE II. Simulation conditions

\begin{tabular}{lr}
\hline House dimensions & \\
\hline Floor area & $210\left[\mathrm{~m}^{2}\right]$ \\
Wall area & $230\left[\mathrm{~m}^{2}\right]$ \\
Roof area & $220\left[\mathrm{~m}^{2}\right]$ \\
Window area & $40\left[\mathrm{~m}^{2}\right]$ \\
Extra heat sources & $0[\mathrm{~kW}]$ \\
\hline Heat exchanger specifications & \\
\hline Area & $0.9\left[\mathrm{~m}^{2}\right]$ \\
Num. of plates & $30[-]$ \\
Sec. dimensioned flow rate & $0.32[\mathrm{~kg} / \mathrm{s}]$ \\
Incoming primary temp. & $100\left[{ }^{\circ} \mathrm{C}\right]$ \\
Returning primary temp. & $50\left[{ }^{\circ} \mathrm{C}\right]$ \\
Incoming secondary temp. & $45\left[{ }^{\circ} \mathrm{C}\right]$ \\
Returning secondary temp. & $60\left[{ }^{\circ} \mathrm{C}\right]$ \\
Power & $20[\mathrm{~kW}]$ \\
\hline \multicolumn{2}{l}{ Radiator circuit } \\
\hline Total radiator power & $17[\mathrm{~kW}]$ \\
\hline
\end{tabular}

TABLE III. Wall specification

\begin{tabular}{l|rrrr}
\hline Wall layer & $\begin{array}{r}\text { Density } \\
{\left[\mathrm{kg} / \mathrm{m}^{3}\right]}\end{array}$ & $\begin{array}{r}\text { Thickness } \\
{[\mathrm{m}]}\end{array}$ & $\begin{array}{r}\text { Spec. heat } \\
\text { capacity } \\
{[\mathrm{J} / \mathrm{kgK}]}\end{array}$ & $\begin{array}{r}\text { Thermal } \\
\text { conductivity } \\
{[\mathrm{W} / \mathrm{mK}]}\end{array}$ \\
\hline Plaster board & 950 & 0.012 & 840 & 0.16 \\
Insulation & 25 & 0.2 & 1000 & 0.035 \\
Air & 1.4 & 0.05 & 1005 & 0.022 \\
Brick wall & 1700 & 0.15 & 800 & 0.84 \\
\hline
\end{tabular}

can be studied in Fig. 14, observe the thermal inertia caused by the heat capacitive effect of the wall.

During simulation, it is very easy to study where the big energy losses are, and how they could be prevented by adding extra insulation or replacing single glass windows to dual or triple glass windows.

The model also supplies very good prerequisites to test and evaluate different control methods for energy optimization purposes, which also were the main purpose of creating this model.

To create a theoretical model is one thing. To believe in it, we need to validate it. Due to space limitation we have chosen to leave this to another paper. However, the validation has been on going with a single detached house in Northern Sweden. We here briefly describe the setup and results.

The measurement system samples and stores data from all flow meters with a frequency of $1 \mathrm{~Hz}$.

To verify the simulation results, high accuracy ultrasonic flow meters with embedded temp sensor have been installed in the villa the model was created to resemble. The flow meters are custom made for this research project by D-Flow [14]. The flow meters are designed to have a maximum flow of $1.5\left[\mathrm{~m}^{3} / \mathrm{s}\right]\left(q_{p}=1.5\left[\mathrm{~m}^{3} / \mathrm{s}\right]\right)$. The flow sensors fulfills the EN-1434 class 2 classification [15] which means that the error range is $E_{f}= \pm\left(2+0.02 q_{p} / q\right) \%$, but not more than $\pm 5 \%$. The temperature sensors connected to the flow-meters are 12 bit digital sensors from Dallas Semiconductor [17] which has a temperature range from $-55^{\circ} \mathrm{C}$ to $125^{\circ} \mathrm{C}$. In the range -10 to $85^{\circ} \mathrm{C}$ they have an accuracy of $\pm 0.5^{\circ} \mathrm{C}$.
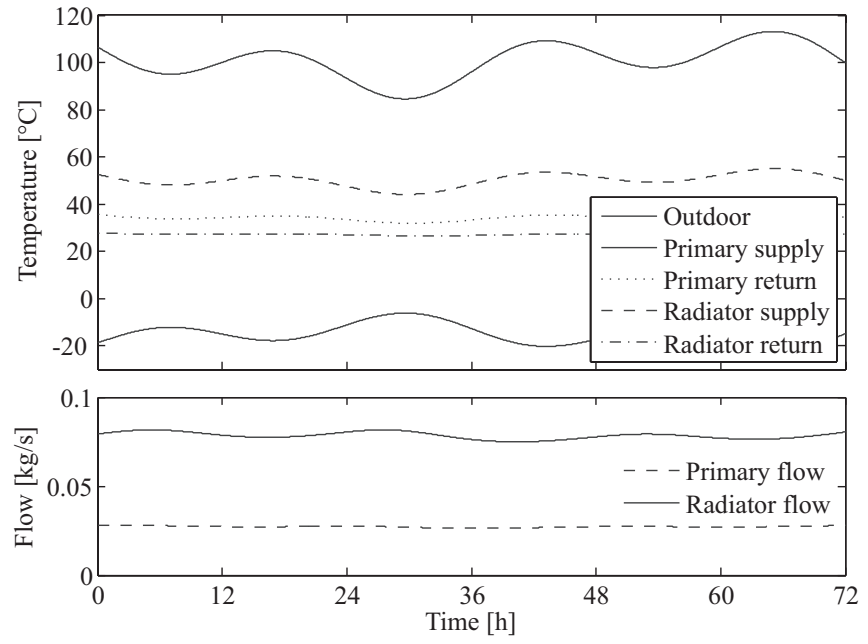

Fig. 13. Temperatures and flows in the space heating heat exchanger.

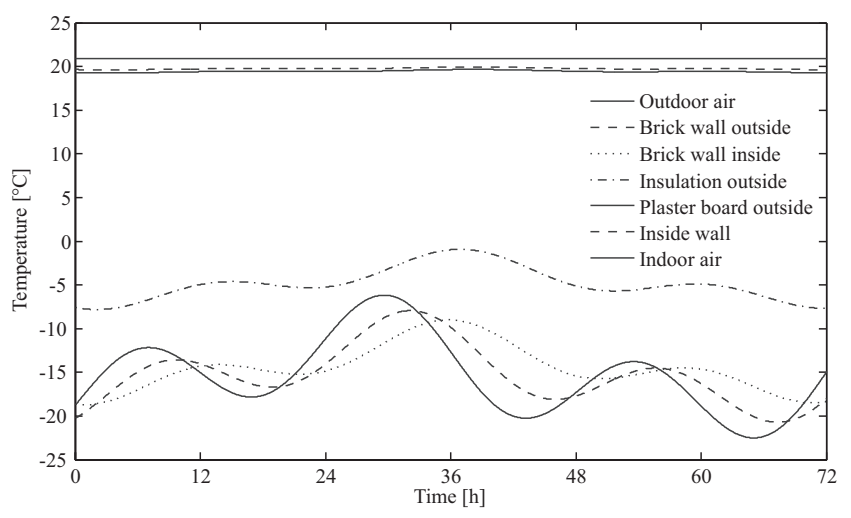

Fig. 14. Wall temperatures.

Supplying the model with measured primary supply temperature, current outdoor temperature and indoor set temperature we can compare the simulation results directly with the measured results, see Fig. 15. Unfortunately we did not have accurate outdoor temperature data for the time of interest available upon the writing of this paper, so an estimate of the outdoor temperature was made. This estimation makes the simulation comparison a bit insecure, and we estimate that this is why the simulation result have a bad fit to the measured data in Fig. 15 between $\sim$ 17: 00 and 01: 00 .

Physical simplifications have been made to keep the computation time down to a reasonable level. The computation time of the current model is approximately 2.5 minutes for a three day simulation, which we find acceptable running on a laptop, with an Intel Centrino Duo processor at $2.16 \mathrm{GHz}$ and $2 \mathrm{~GB}$ RAM. The Simulink version used during these simulations is the one released together with MatLab $\mathbb{R}$ R2007b, the acceler-

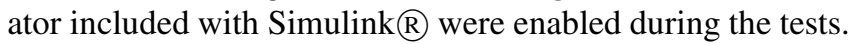

The developed model can be used to simulate a whole block of separate buildings and possibly whole sections of a dis- 


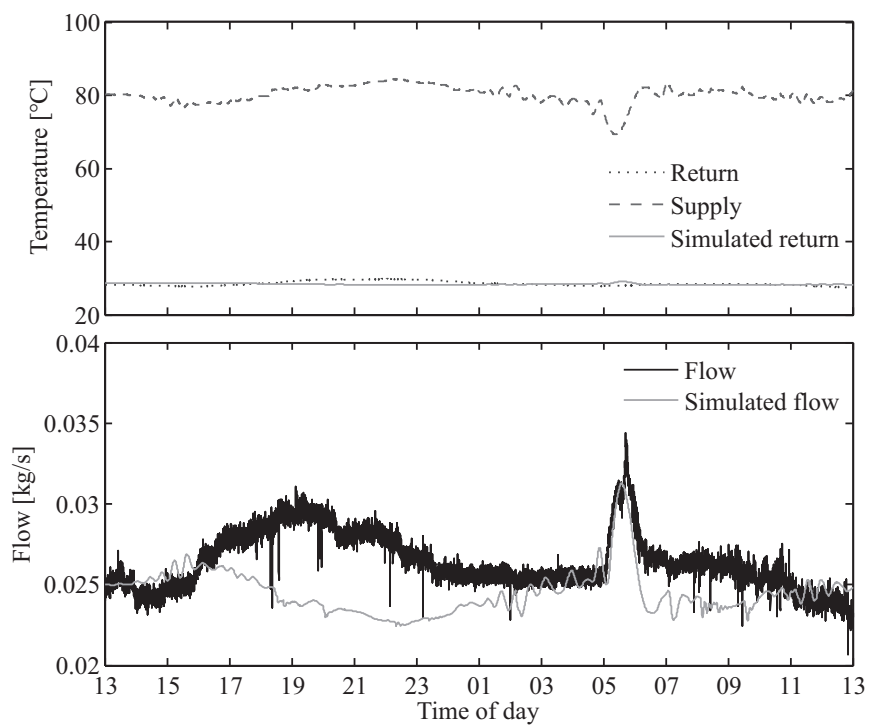

Fig. 15. Radiator circuit verification. The outdoor temperature is around $-3^{\circ} \mathrm{C}$ during this period of time.

trict heating network. By using more dedicated computational serves or even a cluster machine very large problems can be evaluated in reasonable time.

\section{CONCLUSIONS AND DISCUSSION}

In this paper, we describe the implementation of a detached house in MathWorks Simulink(R). This implementation is simple yet powerful as it is descriptive of the construction. By connecting several house models, larger parts of district heating networks is possible to simulate.

The simulation results gives us indications that model respond realistic, the first comparison to real world measurements also confirms this.

For our purpose, we developed the model to evaluate new control methods to maximize the energy transfer in district heating substation. That is the transfer of heat from the primary network to the radiator circuit and the hot tap water system. This can be done by controlling the valve within the primary circuit but also the pump in the radiator circuit.
The model can also have other application as it empowers e.g. an architect to simulate and predict the energy need of a house depending on its construction (e.g. wall structure and windows).

The model is fully functional by theory, and the current validation tests looks promising. Further comparison to real data will be made. The model will now serve in the evaluation of alternative control schemes based on sensor network targeting increased $\Delta \mathrm{T}$.

\section{ACKNOWLEDGMENT}

The writers would like to thank the Swedish District Heating Association for supporting and funding this project.

\section{REFERENCES}

[1] A. Bejan, A. D. Kraus, Heat transfer handbook, John Wiley and Sons, Inc., Hoboken, New Jersey, 2003.

[2] S. Fredriksen, S. Werner, Fjärrvärme, Teori, teknik och funktion., Studentlitteratur, Lund, Sweden, 1993.

[3] J. Wollerstrand, P. Ljunggren, P-O. Johansson, "Optimal reglering av radiatorsystem", Svensk fjärrvärme AB, Fjärrsyn Rapport 2007:6, Stockholm, Sweden, 2007.

[4] K. Yliniemi, Fault detection in district heating substations, Licentiate Thesis, Div. of EISLAB, Dept. of Computer Science and Electrical Engineering, Luleå University of Technology, SE-971 87 Luleå, Sweden, 2005.

[5] P. Ljunggren, Optimal och robust drift av fjarrvarmecentraler, Licentiate Thesis, Div. of energy economics and planning, Dept. of Heat and Power Technology, Lund Institute of Technology, Lund University, Sweden, August, 2006.

[6] T. Persson, District heating for residential areas with single-family housing - with special emphasis on domestic hot water comfort, Ph.D. Thesis, Div. of energy economics and planning, Dept. of Heat and Power Technology, Lund Institute of Technology, Lund University, Sweden, June, 2005.

[7] B.Yu, A.H.C. van Paassen, "Simulink and bond graph modeling of an airconditioned room", Simulation Modelling Practice and Theory, 12 , pages 61-76, 2004.

[8] International District Energy Association, November, 2007. http://www.districtenergy.org

[9] The Swedish District Heating Association, November, 2007. http://www.svenskfjarrvarme.se

[10] J. Berglund, The Swedish district heating association, personal communication, February, 2008.

[11] Y. A. Cengel, Thermodynamics and heat transfer, McGraw-Hill, 1997.

[12] G. Sparr, A. Sparr, Kontinuerliga system, Studentlitteratur, 2000.

[13] H. D. Young, R. A. Freedman, University Physics, Addison Wesley Longman, 2000.

[14] D-Flow, personal communication, February, 2008.

[15] SS-EN 1434, Swedish standard.

[16] SS-EN 442, Swedish standard.

[17] Maxim Integrated Products, Dallas Semiconductor, February, 2008 http://datasheets.maxim-ic.com/en/ds/DS18B20.pdf. 